\section{EVERYTHING YOU NEED TO RUN A TIGHT SHIP}

To help practices achieve their aims Henry Schein Dental offer local account managers supported by teams of dedicated product specialists. The Henry Schein Dental team has years of expertise across a range of disciplines, making them the perfect choice to assess your needs and ensuring they deliver the solutions best suited to your practice.

So whether you need help with decontamination, digital imaging, surgical equipment, implants, whitening products, service and repairs or even business support, Henry Schein Dental can provide the answer to help you run a more efficient and profitable practice.

Visit the team on stand K19 at the British Dental Conference and Exhibition and find out more about how to maximise the benefits of integrating 3D imaging, CEREC and implants into your practice.

For great deals, special offers and to find out more about Everything Dental visit www. henryschein.co.uk.

\section{NEW GENERATION CEMENTS}

DMG UK are exhibiting all their latest innovations including their NEW PermaCem 2.0 on stand D27. They are also celebrating the 20th birthday of their Luxatemp range of bisacryl composite temporary crown and bridge materials.

PermaCem 2.0 represents a completely new generation of self-adhesive luting cements and is perfect for use with all crown and bridge restorations including zirconia-based allceramic restorations.

PermaCem 2.0 achieves an exceptional adhesive strength to other materials as well.

For further information visit stand D27 or go to www.dmgdental.com.

\section{GOOD ORAL HEALTH FOR EVERYONE}

Visit stand G2 at the British Dental Conference and Exhibition to discover more about the benefits of Sensodyne Repair \& Protect. This daily use toothpaste contains NovaMin technology, which builds a reparative layer over your patients' exposed dentine to prevent dentine hypersensitivity with twice daily brushing.

New Poligrip for Partials is a range which has been designed specifically for partial denture wearers, to help them clean their denture and help protect their remaining dentition as part of an oral care routine.

GSK have also sponsored a series of hot tip lectures as part of the conference programme, focusing on preventative dentistry and the new dental contract. Lectures include:

- Helping smokers stop: the role of the dental team in smoking cessation
- Recording periodontal health - a practical guide to the Basic Periodontal Examination

- Tooth surface loss recognising the signs and recording the progress

- Dentine hypersensitivity getting patients to tell you about their pain

- Dry mouth and its impact on sufferers.

Regime Sensodyne Repair \& Protect and Poligrip packs and information on GSK's other oral care brands will also be available. To request trial sized packs of GSK products for your patients visit www.gskdentalprofessionals.co.uk.

\section{ELIMINATING CUMBERSOME TECHNIQUES}

DENTSPLY is set to unveil the Protaper Next at the British Dental Conference and Exhibition 2013. Delegates will also have the opportunity to learn about many of DENTSPLY's leading products.

Among the other products that will be on display is the bulkfill flowable composite Smart Dentine Replacement (SDR). SDR simplifies posterior restorations by eliminating the cumbersome layering technique, as it can be used to bulk-fill in increments of $4 \mathrm{~mm}$, saving the clinician time and effort.

To find out more about DENTSPLY's innovative product range, delegates should be sure to visit DENTSPLY at stand I14.

Visit www.dentsply.co.uk or call 0800072 3313; earn rewards against purchases at www. dentsplyrewards.co.uk; access webinars and product demonstrations and earn CPD at www. dentsplyacademy. co.uk

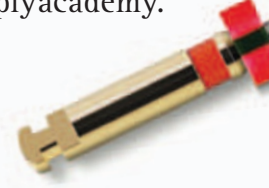

\section{REIGNITE YOUR PASSION FOR DENTISTRY}

Find out your next steps for career success and visit the UCL Eastman stand at the British Dental Conference and Exhibition. Talk to the knowledgeable team and try the hands-on demonstrations for a fuller appreciation of the standard of teaching. UCL Eastman continually develops new and existing programmes for exciting, relevant and high-impact training. Courses are flexible, complementing busy lifestyles, and suitably challenging to reignite passion for dentistry.

Take advantage of outstanding facilities, a highly experienced faculty, a variety of accomplished guest tutors, superior hands-on training, and tangible benefits to implement into the practice.
A leader in student-centred education, UCL Eastman offers a range of short, part-time, full-time and distance learning programmes. Delegates can gain Masters degrees, specialty training, certificates, diplomas and research doctorates plus verifiable CPD.

For taught or research programmes, telephone 020 34561155 or email ediadmissions@ucl.ac.uk. For CPD and online programmes, telephone 02079051234 or emailedi-cpd@ucl.ac.uk. 